\title{
ENTRAVES E PERSPECTIVAS DE UM CURSO DE FORMAÇÃO SOBRE ECONOMIA SOLIDÁRIA EM UNIVERSIDADES: RELATO DE CASO
}

\author{
BARRIERS AND PERSPECTIVES OF A SOLIDARITY ECONOMY TRAINING \\ COURSE AT UNIVERSITIES: A CASE REPORT
}

Sanyo Drummond Pires ${ }^{1}$

Renan Gabriel Oviedo Silveira ${ }^{2}$

Recebido em 03/03/2020

Aceito em 09/06/2020

Resumo: O presente artigo apresenta os resultados de um projeto de extensão estruturado como curso, voltado para a capacitação na área da Economia Solidária. Inicialmente voltado para capacitar membros de gestões municipais e estudantes universitários, o projeto foi marcado por uma série de problemas, que levaram à sua extinção prematura, e não consecução total dos objetivos propostos. Os problemas enfrentados foram então analisados a partir de uma reflexão sobre as formas de institucionalização da relação da universidade pública, e principalmente das incubadoras, com a economia solidária. Ao final do artigo são feitas propostas de revisão do modelo de institucionalização dessa relação, e sugeridas ações específicas que poderiam ser adotadas.

Palavras-chave: Economia Solidária, Formação, Parcerias Públicas, Universidade.

Abstract: This article presents the results of an extension project structured as a course, focused on the capacity for solidarity economy. Initially aimed at municipal management members and university students, the project was marked by a series of problems, which was taken to its premature extension, and was not the full achievement of the proposed objectives. The problems faced were analyzed based on a reflection on the forms of institutionalization of university public relations, and mainly of incubators, with a solidary economy. At the end of the article, proposals are made to revise the institutionalization model of this relationship, and specific actions that can be taken are suggested.

Keywords: Solidarity Economy, Training, Public Partnerships, University.

\footnotetext{
${ }^{1}$ Docente da Faculdade de Ciências Humanas da Universidade Federal da Grande Dourados - UFGD.

${ }^{2}$ Graduando da Faculdade de Ciências Humanas da Universidade Federal da Grande Dourados - UFGD.
} 


\section{INTRODUÇÃO}

A questão da capacitação se constitui como um tema a parte dentro da economia solidária. Por demandar formas de pensar e agir diferentes das formas relacionadas à produção em empresas capitalistas ou em entidades estatais ou caritativas, a transmissão de informações e conhecimentos decorrentes dos acúmulos possibilitados pelas experiências já existentes dos empreendimentos de economia solidária (EES) e dos diversos atores e entidades sociais a eles ligados, se mostra como fator importante para que erros já vivenciados e compreendidos não precisem ser repetidos.

Esse acúmulo se refere a diferentes campos de conhecimento, que vão desde elementos técnicos, relacionados a questões de revisão sociotécnica do processo produtivo, ou processos de gestão e controle fiscal dos EES, até elementos políticos, comportamentais ou linguísticos, relacionados à compreensão e adesão a valores que fundamentam a economia solidária. Da mesma forma, esses acúmulos também se referem à relação da economia solidária com temas transversais, como meio ambiente, modos de consumo, relações de gênero, raça, etnia, idade, entre outros.

Porém, a essa pluralidade de campos de conhecimento a serem transmitidos, é importante acrescentar também a pluralidade de atores, que desempenham diferentes papéis na economia solidária como um todo, e a consideração das especificidades de conhecimento que cada um desses atores demanda para que seus papéis possam ser executados. Nesse sentido, os processos de capacitação precisam ser pensados a partir dessas diferentes demandas, o que nos remete a pensar a economia solidária a partir de sua complexidade e da necessidade de uma análise crítica dos processos de divisão técnica e social do trabalho no seu interior.

O presente artigo se propõe a analisar uma experiência de formação em economia solidária voltada principalmente para gestores públicos e estudantes, com o intuito de inseri-los de maneira mais sistemáticas na elaboração e execução de projetos conjuntamente com a Incubadora de Tecnologias Sociais e Solidárias da UFGD (ITESS/UFGD). Embora o curso não tenha alcançado os resultados esperados, as percepções decorrentes da experiência podem servir como elementos de análise para que futuros processos de capacitação, que sejam destinados a públicos semelhantes, possam ocorrer de maneira mais efetiva em outros projetos. 


\section{2 - CONTEXTO DO PROJETO}

O projeto se estruturou a partir de um edital interno da UFGD, destinados a projetos de extensão. Ao momento do projeto, com a iminente perda de mandato da Presidente Dilma Roussef, havia a perspectiva, posteriormente confirmada, de um processo de desarticulação das políticas sociais dos governos petistas, e dentre elas, a desestruturação da Secretaria Nacional de Economia Solidária (SENAES), e consequentemente do Programa Nacional de Incubadoras de Cooperativas Populares (PRONINC), principal programa de financiamento e fomento às incubadoras de economia solidária e de tecnologias sociais.

Frente à perspectiva de perda de financiamento para novos editais e projetos, o curso foi estruturado para buscar fortalecer parceria com o poder público municipal, ou outras entidades públicas, que poderiam desenvolver soluções para suas demandas tendo a economia solidária como uma de suas alternativas. Para fortalecer essas parcerias, intencionava-se capacitar técnicos dessas entidades de forma a disseminar um maior conhecimento sobre a economia solidária e sobre as possibilidades de incubação dos empreendimentos e processos solidários (PIRES, 2017). Com isso, esperava-se que, a partir da maior compreensão da economia solidária e de sua aplicação em processos de desenvolvimento econômico e inserção social, os agentes ligados ao poder público pudessem melhor visualizar projetos a partir dessas perspectivas e estruturar demandas a serem direcionadas à ITESS, que se estabeleceriam por meio de parcerias.

Da mesma forma, o projeto visava também preparar alunos que, já compreendendo e convivendo com as demandas e reflexões apresentadas pelos agentes das entidades públicas, pudessem aprender sobre a economia solidária de maneira mais aplicada, e prepararem-se para assumir funções de extensão e pesquisa nos projetos decorrentes das parcerias. Com isso pretendia-se criar um ciclo onde a capacitação de alunos para atuar em projetos de economia solidária já estivesse articulada com o pensar políticas públicas, que por sua vez poderiam ser realizados por eles também após se formarem, caso ocupassem funções públicas, demandando novas parcerias com a ITESS.

Com isso, duas ações norteavam a elaboração dos cursos. Preparação de agentes públicos e de estudantes para conhecerem melhor a economia solidária, e a busca de estruturação de projetos práticos que levassem a parcerias com entidades públicas locais, 
que sustentariam projetos durante o período de desarticulação da economia solidária no governo federal.

\section{3 ï CONTEXTO DA ECONOMIA SOLIDÁRIA EM DOURADOS E NA}

\section{UFGD}

A Economia Solidária alcançou um desenvolvimento significativo no município de Dourados, principalmente entre 2003 e 2006, quando uma série de empreendimentos foi criada. Estes, de tipos variados, impulsionaram a estruturação tanto instituições próprias quanto de políticas públicas ligadas ao tema. Um fator de destaque também foi a adoção da economia solidária como um dos elementos de atuação de entidades não governamentais.

Houve então uma série de conquistas, como a Criação da Secretaria Municipal de Economia Solidária, do Fórum Municipal de Economia Solidária, e do Conselho Municipal de Economia Solidária, além da consecução de espaços financiados com subvenção pública municipal para a comercialização de produtos, além de espaços para comercialização em eventos e feiras periódicas. No entanto, a imensa maioria dos empreendimentos criados, se caracterizava por sua simplicidade e informalidade, gerando renda inferior a um salário mínimo para seus membros, sendo comum a busca de renda também em outras formas de ação, como prestação de serviços ou empregos nos moldes tradicionais (SÁ, 2005; VERÃO, 2016, RIEDO, RIBEIRO, CALARGE, 2019).

Esses empreendimentos podem ser agrupados em dois tipos principais. Os urbanos, geralmente localizados em bairros periféricos da cidade, criados com apoio de grupos religiosos, marcados por baixa qualificação profissional, de caráter informal e que buscam se estruturar como alternativas de geração ou complementação de renda para seus associados, excluídos ou inseridos de forma precarizada no mercado de trabalho, principalmente na confecção de produtos feitos artesanalmente. $O$ segundo tipo são empreendimentos rurais, principalmente ligados a assentamentos rurais em Dourados ou nas cidades da região, e contam com a terra como fonte de produtos. No entanto, na sua maior parte, mantêm a dimensão artesanal da produção, geralmente comercializando os excedentes, não havendo a inserção de métodos sistemáticos de gestão voltados para aprimorar os resultados econômicos na organização dos empreendimentos, como é comum em cooperativas de produtores rurais (FERNANDES et al, 2014;




LOBTCHENKO et al, 2018; DâELIA et al, 2012; MASCARELLO, MASCARELO, 2016).

No momento atual essas conquistas vêm se desestruturando, principalmente com a extinção da Secretaria Municipal de Economia Solidária, que recebia e encaminhava demandas do Fórum e do Conselho de Economia Solidária, diminuindo o alcance dessas entidades em termos de elaboração de políticas públicas. A criação de empreendimentos também diminuiu após o ano de 2007 (VERÃO, 2016) e, embora ainda surjam novos empreendimentos solidários, não se pode afirmar que seja uma proposta em expansão.

Dentro do contexto do desenvolvimento da Economia Solidária no município de Dourados, podemos perceber também o papel das universidades, principalmente a UEMS e a UFGD. Essa atuação se organizou por meio de duas frentes. Primeiro, por parte das duas incubadoras; a Incubadora de Tecnologias Sociais e Solidárias (ITESS) da UFGD, criada em 2006 e a ELOS, Incubadora Tecnológica de Cooperativas Populares (ITCP) da UEMS, criada em 2007, ambas ligadas institucionalmente às pró-reitorias de extensão das universidades. (RIEDO, RIBEIRO, CALARGE, 2019). Estas incubadoras foram responsáveis tanto por projetos de extensão quanto por projetos de pesquisa, principalmente associados aos editais de fomento de pesquisa e extensão direcionados às incubadoras. Em segundo lugar, podemos destacar as atividades de pesquisa realizadas sobre o tema em alguns programas de pós-graduação stricto senso, principalmente na UFGD.

No entanto, apesar de ter havido um sistemático desenvolvimento da economia solidária nessas duas frentes, é preciso ponderar essas ações a partir de uma compreensão um pouco mais detalhada. A maior parte da produção acadêmica em economia solidária apresenta grande variação conceitual sobre o que é economia solidária e sobre o que seria sua efetiva implementação, o mesmo acontecendo com a dimensão metodológica. Além disso, não se configura como uma atividade nem sistemática nem central para a maioria dos pesquisadores. Isso se expressa de maneira mais clara quando consideramos a publicação de artigos na área. Na sua maioria, esses artigos representam produções esporádicas (ou únicas) e secundárias dos autores, ligadas a outros temas que são centrais em suas áreas de pesquisa (como gênero, ecologia, ou saúde mental), relegados às revistas com baixa avaliação (OLIVEIRA e ZANIN, 2011, CALBINO e PAULA, 2013; SILVA, ZANIM, 2018, SILVA, 2018). 
Embora não tenhamos realizado uma análise sistemática da produção sobre o tema na UFGD e na UEMS, em um levantamento superficial sobre essa produção nas duas universidades pudemos encontrar uma situação que não é diferente do contexto geral da produção no resto do país. Da mesma forma, o processo de surgimento das incubadoras, está associado também ao momento de maior desenvolvimento da economia solidária no município. Além disso, como nos mostra Victória (2011), essa criação parece estar atrelada a um processo de expansão, ocorrida nos anos de 2005 e 2006, das políticas públicas que tinham a economia solidária como base, com a articulação das ações da SENAES com outras secretarias e ministérios, o que levou à estruturação de novos editais com demandas de apoio técnico universitário em áreas tradicionais, mas agora sob um viés que envolvia também a economia solidária.

O que é interessante notar nesse quadro, é que as ações de economia solidária nas universidades, bem como as suas formas de institucionalização, estavam atreladas a editais voltados para o tema da economia solidária, mas muitas vezes articulados com outras temáticas. Tal fato, embora desenvolvesse a construção de um acúmulo teórico e metodológico sobre a Economia Solidária não gerou a estruturação de ações específicas como a criação de linhas de pesquisa, disciplinas teóricas ou laboratórios específicos sobre o assunto. Mesmo a estruturação das incubadoras pode ser nesse quadro compreendida na sua função de captação de recursos, que, ainda que tenham destacado a temática da economia solidária, serviram também de base para o desenvolvimento de projetos que tinham a economia solidária como um elemento secundário nas suas formulações.

Um reforço a essa interpretação foi a desestruturação das incubadoras com o início do processo de impedimento do governo da presidenta Dilma, e a posterior extinção da SENAES, que gerou uma diminuição drástica nos editais voltados para o tema, e a consequente desmobilização dos pesquisadores que antes sustentavam projetos nas incubadoras, e a desestruturação da incubadora da UEMS, e a absorção da ITESS/UFGD em um sistema mais amplo de incubadoras.

\section{4 ï FORMAÇÃO EM ECONOMIA SOLIDÁRIA.}

Os processos de geração de trabalho e renda por meio da economia solidária, geralmente encontram duas grandes dificuldades. A primeira é a manutenção de 
mecanismos defensivos (tanto institucionais quanto psicossociais) adaptados à situação de heterogestão para o contexto do trabalho autogestionário, o que, além de não defender os trabalhadores dos elementos agressivos da organização do trabalho nessa nova forma de estruturação produtiva, cria vários outros problemas (PIRES, 2018). O segundo é a utilização de conceitos construídos para explicar dinâmicas heterogestionárias para tentar compreender as dinâmicas vivenciadas nas experiências autogestionárias, que além de não possibilitarem um entendimento efetivo das atividades em análise, acabam por levar à reprodução de situações de dominação e injustiça que se tenta superar, o que Chauí (1986) denominou Consciência Social Trágica.

Dentro desse contexto, as incubadoras universitárias de tecnologias sociais ou de economia solidária cumprem uma importante função, pois são os espaços onde as ações dos trabalhadores se encontram com os espaços de reflexões acadêmicos, possibilitando tanto o aproveitamento e canalização dos conhecimentos já presentes no cotidiano dos trabalhadores quanto o desenvolvimento de novas propostas de produção que melhor se adequem à realidade dos mesmos e aos seus interesses (OLIVEIRA, ADDOR, MAIA, 2018).

As incubadoras universitárias vão, por meio da transmissão de competências técnicas, gerenciais, políticas, e culturais presentes na universidade, buscar superar as condições de assujeitamento impostas pelos trabalhadores pela organização heterogestionária do trabalho, e pela trajetória de precarização da vida e das relações de trabalho às quais esses trabalhadores sempre foram expostos. A ação da incubadora então, ao buscar a superação e o desenvolvimento de outro modelo de organização do trabalho, em conjunto com os trabalhadores, visa possibilitar um processo de empoderamento que apesar de se aplicar inicialmente ao trabalho se expande também para outras áreas da vida do sujeito (GATTAI, BERNARDES, 2013).

O que se busca então nos processos de incubação é que ocorra um processo de reflexão no qual vivência do real do trabalho que os trabalhadores possuem em seu cotidiano se articule com o acúmulo de conhecimentos técnicos e sociais dos quais a universidade é depositária. Nesse sentido, as ações de extensão da universidade devem se estruturar a partir de uma metodologia que possibilite a participação ativa daqueles para quem a extensão se destina, de forma que, não só um conhecimento ou tecnologia possa 
ser levado à comunidade, mas também o processo de reflexão sobre esse conhecimento ou tecnologia (THIOLLENT, 2002).

Na formação para a economia solidária, então, além de um processo de aquisição de conhecimentos que possibilitem novas formas de pensar o trabalho, e a organização produtiva (TIRIBA, 2004), é importante que os projetos de extensão universitária no qual a capacitação dos trabalhadores se constitua também em espaços onde os trabalhadores sejam chamados a repensarem a própria universidade de maneira ativa, participando da definição das formas de se apropriar da sua função de extensão do conhecimento.

Dentro dessa perspectiva, no presente projeto, a intenção era que, mais do que levar o conhecimento sobre a economia solidária para a população, construísse condições para que um grupo específico, os técnicos ligados ao poder público municipal, pudessem se qualificar para se constituírem em coautores de projetos e da reflexão sobre o processo de incubação. Com isso, pretendia-se que a função de realizar esse planejamento, além de não se resumir a uma ação da universidade, envolvendo os poderes públicos locais, também criasse uma cultura de integração universidade / poder público, a partir de relações mais equânimes e processos de comunicação mais bem estruturados.

\section{5 - AÇÕES PRÉ-EXECUÇÃO DO PROJETO.}

A demanda de criação do curso partiu de uma análise conjuntural que previa a perda do fomento à pesquisa e extensão para as incubadoras de tecnologias sociais e economia solidária, decorrente da eminente desarticulação das SENAES. Frente tal quadro, identificou-se nas parcerias com o poder público e outras entidades locais, alternativas que poderiam não só fomentar financeiramente os projetos, mas também estabelecer parcerias para suas execuções, gerando processos de enraizamento tanto de ações quanto de concepções da economia solidária nos municípios da Grande Dourados. Com isso pretendia-se superar os ciclos nos quais a perda de fomentos vindos do governo federal ou do estado gerasse, no âmbito local, a desarticulação e perda dos acúmulos tanto conceituais, econômicos e institucionais, obtidos nos momentos onde esses fomentos estavam disponíveis.

Foi estruturado então o projeto de extensão, ligado a Incubadora de Tecnologias Sociais da UFGD ï ITESS/UFGD, denominado ñCapacitação Avançada em Economia Solidáriaò. Era um curso de cento e oitenta horas com o intuito de capacitar tanto os 
profissionais de órgãos públicos para o desenvolvimento de projetos na área de economia solidária em suas respectivas áreas de atuação, com vistas ao estabelecimento de parcerias com a ITESS/UFGD, quanto na qualificação de estudantes da UFGD e de outras universidades na região da Grande Dourados, para a participação como bolsistas nos futuros projetos de pesquisa e extensão.

O curso foi planejado para ter módulos com temas variados, que se dividem em três grupos: módulos teóricos, abordando aspectos conceituais gerais e repassados as experiências históricas de reflexão sobre a economia solidária e seus processos de institucionalização; módulos aplicados, articulando a economia solidária a outras questões sociais, como gênero, saúde mental, ecologia, entre outros; e os módulos práticos, discutindo aspectos técnicos de estruturação e gestão de empreendimentos e projetos em economia solidária.

Paralelo à atividade das aulas, foi também planejado um processo de autoavaliação para verificar o desenvolvimento das concepções acerca da economia solidária e da estruturação do curso como instrumento de mediação, compreendida a partir da perspectiva Sócio-Histórica, para a ressignificação que essas novas concepções proporcionavam. A autoavaliação seria realizada entre o final de cada módulo e o inicio do seguinte, individualmente, por meio de um texto redigido pelos alunos, que expressasse sua compreensão sobre os temas discutidos, comparando com a anterior ao curso, e sobre a forma como as aulas foram conduzidas. Essa atividade de avaliação se configuraria como uma atividade a ser conduzida em parceria com a ELOS/UEMS.

Foi estabelecido, como público prioritário para o curso, agentes de órgãos públicos, alunos da UFGD e da UEMS e pessoas ligadas a projetos sociais na área da economia solidária, respectivamente; sendo aberto, também, para outros participantes, caso houvesse vagas não ocupadas pelo público prioritário. O processo de divulgação, então, foi feito através de plataformas virtuais, bem como por meio de contato direto com as secretarias responsáveis e com as prefeituras da região. No primeiro caso, houve a difusão de um link que proporcionava o acesso a uma descrição detalhada do curso; isso foi feito via páginas oficiais da UFGD, da UEMS e da ITESS/UFGD e via perfis pessoais dos pesquisadores e colaboradores do projeto. No segundo, a comunicação foi feita por e-mails, ligações e visitas aos locais referidos. Além disso, foi concedida uma entrevista 
à TV Morena, afiliada local da Rede Globo, na qual foram dadas explicações sobre a economia solidária e sobre o curso.

A questão que julgamos mais relevante nos foi colocada pela Secretaria de Assistência Social de Dourados, que já antevia a necessidade de que o curso se configurasse como uma pós-graduação. A titulação obtida com o curso geraria aumentos salariais para os funcionários, sendo assim um fator motivador para a participação no mesmo. A configuração enquanto projeto de extensão poderia ser prejudicial ao curso, pois os funcionários prefeririam investir o tempo relativo a este curso em outros que resultassem em tal certificação.

$\mathrm{Na}$ proposta inicial, o curso teria longa duração, e esta característica poderia resultar em um intenso processo de evasão. Pretendia-se, então, iniciar o curso com oitenta participantes, na expectativa de que, mesmo com uma alta evasão, um número alto de inscritos se mantivesse ativo. No entanto, devido a limitações de espaço ï inicialmente, foi definido o Auditório da Reitoria, localizado na Unidade I da UFGD, local mais centralizado na cidade $\ddot{I}$ as vagas foram reduzidas para 40 pessoas, que poderiam ser mais facilmente alocados em uma das salas de aula localizadas nessa mesma Unidade. Os horários também foram modificados, pois as salas a serem usadas, estariam ocupadas por outras atividades no período da manhã, o que nos levou a realizar os encontros nos sábados à tarde e nos domingos pela manhã.

\section{6 ï AÇÕES DE EXECUÇÃO DO PROJETO}

\section{Seleção dos participantes.}

Com a divulgação do curso, as inscrições foram realizadas online, a partir de um link na página onde havia a explicação sobre o curso, no site da UFGD. Ao fazer a inscrição a pessoa, além de dados pessoais básicos, incluindo área e nível instrucional e vinculação institucional, explicava em poucas palavras sua compreensão sobre a economia solidária, e a expectativa com o curso. Ao todo houveram 113 inscrições, com público variado.

Foram então selecionados os que possuíam as características desejadas, na ordem indicada anteriormente. Desse total houveram 23 inscritos ligados a entidades públicas, sendo 14 de Dourados, e o restante de cidades próximas. Houveram também 8 inscritos

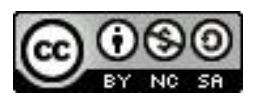


de entidades sociais que desenvolviam projetos de economia solidária. Quanto aos estudantes, foram um total de 3 estudantes de programas de mestrado, todos da UFGD, do programa de Sociologia, e 28 alunos da UFGD, 14 da UEMS, e 18 de outras instituições de ensino. As outras 19 pessoas, na maioria artesãos, gostariam de obter informações para a criação de empreendimentos.

Todos os inscritos selecionados estavam vinculados às categorias membros de instituições públicas ou entidades sociais, bem como aos programas de pós-graduação de várias instituições de ensino superior. Dos alunos de graduação, procurou-se realizar uma triagem a partir da percepção do que era a economia solidária e da expectativa com o curso. Foram retirados os que tinham a expectativa de criar empreendimentos próprios, ou que apresentavam compreensão muito discrepante do que era economia solidária. Ao todo foram selecionados 40 alunos, sendo 20 da UFGD, 8 da UEMS e 12 de outras instituições. Além disso, foram selecionados sete membros dos 19 não ligados ao público alvo, em função de sua perspectiva de participar da elaboração de projetos em outras instituições que não públicas, principalmente instituições religiosas.

Ao todo foram selecionados 81 dos 113 inscritos. O contato com os mesmos foi por e-mail, no qual foram fornecidos dados sobre a realização do curso, como local, datas e dinâmica das aulas. Foi aberto um canal de contato também por meio de um grupo de Facebook, onde poderiam tirar mais dúvidas. Desse total de 81 selecionados somente 43 responderam os questionários de inscrição, que demandava principalmente que os inscritos escrevessem texto de meia a uma página sobre sua compreensão sobre economia solidária. Este texto seria usado como base para avaliação da evolução da compreensão em um segundo momento, no processo de avaliação do curso.

As principais dúvidas, de quem entrava em contato, diziam respeito sobre a possibilidade do curso se configurar como uma pós-graduação, e sobre as datas do curso. Houve também questionamento por parte do grupo de inscritos de uma cidade próxima a Dourados se as atividades não poderiam ser também na cidade onde residiam. A partir de aprofundamento no diálogo sobre as dúvidas, pudemos perceber que parte dos moradores de outras cidades deixou de participar devido à distância para o deslocamento, e funcionários públicos porque o curso não corresponderia ao nível de pós-graduação, como já havia antevisto a Secretaria de Assistência Social de Dourados. 
Com isso, dos 23 inscritos ligados às entidades públicas, somente 8 iniciaram o curso. Dos 8 ligados às entidades sociais, somente 4 iniciaram o curso. Os 3 estudantes de pós-graduação iniciaram o curso. Dos alunos de graduação que iniciaram o curso, 15 eram da UFGD, 3 da UEMS e 5 das demais universidades. Os inscritos, e 5 dos 7 não ligados à grupos prioritários, compondo um total de 43 inscritos de fato que iniciaram o curso. No entanto, é importante frisar que desses já no segundo encontro houve um número significativo de evasão. Dos 43 alunos inscritos, apenas 25 participaram, além da baixa adesão dos participantes de outras cidades. Esse percentual manteve-se ainda por mais dois encontros, até cair para os 15 alunos que participaram até o encerramento do curso.

\section{Execução das aulas}

As aulas ocorreram em uma sala do Campus I da UFGD, localizada na região central de Dourados, aos sábados pela tarde e domingos pela manhã, com um total de quatro horas em cada dia, perfazendo em torno de oito horas-aula por encontro. Além disso, ao final do encontro era proposta uma avaliação da aula e da discussão dos conteúdos estudados, por meio da elaboração de um pequeno texto, perfazendo mais duas horas-aula, o que conferia 10 horas a cada encontro.

Em cada aula era abordado um tema. Os temas iniciais foram: Noção geral de Economia Solidária, Teoria da Dádiva de Mauss, Associativismo e Cooperativismo, Empreendimentos e Processos em Economia Solidária, Análise Sociotécnica do Trabalho. Após o estudo dos temas citados, devido às demandas dos alunos expostas nas atividades de avaliação, percebeu-se ser necessária uma maior fundamentação em conceitos mais básicos sobre o mundo do trabalho. Passou-se então, dos temas previstos a serem trabalhados para a discussão sobre trabalho humano e teoria do valor em Marx, que geraram dois encontros.

\section{Atividades de avaliação das aulas}

A avaliação das aulas era composta de duas atividades. A primeira era dos encontros em si e dos conteúdos estudados, além de refletir sobre a dinâmica ou questões referentes ao aspecto teórico, além de fatores relativos à adequação aos elementos concretos da gestão pública ou de projetos ou empreendimentos em economia solidária já conhecidos. Uma segunda ação era feita por escrito individualmente, e encaminhada por e-mail após as aulas, com as considerações sobre os conhecimentos adquiridos 
durante o encontro. Com essas ações, mais que um processo avaliativo do aluno, pretendia-se obter um processo avaliativo do impacto que o curso gerava, tanto em termos de sua dinâmica, e das demandas que colocavam para os alunos, quanto ao impacto das aulas na mudança da compreensão sobre a economia solidária e sua capacidade de analisá-la a partir dos conceitos desenvolvidos nas aulas.

É importante destacar que essa atividade, inicialmente era planejada para ser mais extensa e consistiria em um subprojeto desenvolvido em conjunto com o curso, por meio da incubadora da UEMS. Na proposta inicial, essas ações de autoavaliação dos conhecimentos obtidos seriam articuladas com a elaboração de um projeto de economia solidária, ligado a uma área pública na qual esses conhecimentos obtidos seriam discutidos de maneira aplicada aos projetos em desenvolvimento.

No entanto, o processo de desestruturação da Incubadora da UEMS, e a realocação da sua técnica (que seria responsável por essas ações) para outras atividades, prejudicou o andamento da proposta. Além disso, com a drástica diminuição do número de participantes ligados ao poder público, e a percepção muito pouco desenvolvida do que era economia solidária, e do poderia ser feito em termos de economia solidária nas administrações públicas, nos levou a adiar essa metodologia. As atividades de avaliação passaram então a ter o objetivo de acompanhamento do processo de desenvolvimento dos alunos, para possíveis revisões.

A partir dos dados dessas avaliações percebeu-se que os módulos mais básicos, com elementos teóricos sobre análise do trabalho eram percebidos como os mais importantes, e geravam mais discussões e avanços nas compreensões dos alunos. Essas conclusões foram obtidas a partir da análise das autoavaliações e dos trabalhos escritos. Nesses últimos era perceptível a dificuldade dos alunos em apresentarem uma análise crítica e criativa das possibilidades de implementação da economia solidária. Identificouse, também, a partir das autoavaliações que as principais dúvidas ou os pontos frágeis na discussão estavam na ausência de elementos conceituais relacionados à noção de trabalho humano e teoria do valor. Foram estruturados então dois encontros sobre esses temas.

\section{7 İ INTERPRETAÇÃO DOS RESULTADOS DAS AÇÕES.}

\section{Desenvolvimento teórico}

A partir da análise dos textos encaminhados inicialmente pelos alunos com sua compreensão sobre economia solidária, foi percebido um baixo nível inicial de 
conhecimento de conceitos subjacentes à economia solidária, embora já houvesse um contato de maior parte dos participantes com empreendimentos de economia solidária ou pessoas que já participaram desses empreendimentos. A partir dos encontros, por meio dos processos autoavaliativos, foi percebido um desenvolvimento significativo da compreensão dos conceitos estudados, bem como uma ressignificação das concepções e vivências anteriores relacionadas à economia solidária. Para essa ressignificação foi conferida grande importância, além dos conteúdos em si, para a discussão entre os participantes do curso, devido à diversidade de formação e de experiências profissionais de cada um deles em relação à economia solidária.

A partir dessas informações, pudemos perceber que a proposta inicial não implementada, de utilizar a elaboração de um projeto como fio condutor do processo de elaboração dos temas trabalhados, a ser realizado por equipes contendo alunos de diferentes perspectivas (membros do poder público, de entidades não governamentais e estudantes de graduação e pós-graduação), poderia ter sido mais explorada. Pudemos perceber também o impacto que processos formativos mais detalhados e profundos podem gerar na compreensão da economia solidária. A maior parte dos participantes já havia participado de palestras ou minicursos sobre economia solidária. No entanto, o simples fato de ser exposto a um conteúdo teórico básico, como Teoria da Dádiva de Mauss, ou das noções de Cooperativismo e Associativismo, pensados em relação à economia solidária, modificava de maneira significativa sua compreensão sobre o tema.

\section{Evasão dos alunos}

O processo intenso de evasão ocorrido durante o curso pode ser analisado como um elemento multidimensional, e associado tanto a problemas inesperados, como aos ligados à infraestrutura quanto ao próprio desenho do curso.

O primeiro deles, decorrente da titulação de especialista esperada por parte do público-alvo, que já nos havia sido alertado. Ao objetivo do curso seria, também, atender alunos de graduação, a modalidade deveria ser a de extensão. Além disso, um número significativo de participantes não apresentava um acúmulo anterior de conhecimentos sobre o tema. Portanto, definiu-se por criar um curso de extensão, e, a partir dos seus resultados práticos e teóricos, verificar a possibilidade de criar um de pós-graduação. No entanto, essa caracterização parece ter sido pouco explicitada, pois, uma parcela 
significativa dos inscritos ainda tinha a perspectiva de que pudesse se transformar em uma especialização, ou ter créditos aproveitados em um futuro curso.

O segundo elemento principal no processo de evasão foi o desenho do curso, pois acontecia durante os fins de semana com um intervalo grande entre eles (geralmente um mês). Esse intervalo foi pensado em função das atividades de elaboração do projeto, que não se concretizou. Portanto, esta opção ficou sem sentido, havendo uma perda de articulação entre os conhecimentos construídos em um encontro e outro, somente no mês seguinte. Além disso, o deslocamento de outras cidades para Dourados e a necessidade de pernoite, se mostraram como obstáculos econômicos para a participação de alguns alunos. A perspectiva de um curso de longa duração, também parece ter sido um elemento prejudicial, principalmente para aqueles em final de formação, que precisariam concluir o curso para o aproveitamento de sua carga horária para conclusão do curso, ou mesmo, no caso de quem concluiria seu curso de graduação e não permaneceria mais em Dourados.

\section{Desarticulação do curso}

Os últimos encontros ocorreram no mês de dezembro, já com menor participação em função do período de fim de semestre, e início das férias escolares. O retorno no ano seguinte, no entanto, não ocorreu devido também a uma série de fatores. O primeiro deles foi o processo de redistribuição do professor coordenador do projeto. Já morando em outra cidade e com a perspectiva de deixar a UFGD, a coordenação do projeto precisaria ser repassada para outro professor, para que as atividades tivessem continuidade. No entanto, devido à desestruturação das SENAES, e o processo de modificação nas concepções da ITESS UFGD, que passava por processo de ressignificação com a criação de outras duas incubadoras na universidade, a maior parte dos pesquisadores anteriormente ligados a ITESS e à temática da economia solidária já redirecionava suas atividades ou para outros temas (geralmente seus temas centrais de pesquisa) ou para outros espaços de reflexão, como projetos de pesquisa ou programas de mestrado e doutorado.

Somado à sobrecarga de atividades relatadas pelos professores ligados ao projeto, que já direcionavam suas atividades para outras temáticas, e da saída de boa parte desses professores para processos de doutorado ou pós-doutorado, encontrou-se então uma 
grande dificuldade para a substituição da coordenação do projeto. Optou-se então pela interrupção das aulas e início da análise dos seus resultados.

\section{CONSIDERAÇÕES FINAIS}

Embora a experiência do curso não tenha sido exitosa em relação aos seus objetivos iniciais, a experiência de sua implementação e os problemas enfrentados podem ser aproveitados para uma maior compreensão da relação da universidade com a Economia Solidária, bem como servir de base para a elaboração de novos projetos. Dentre esses elementos, o que se mostra mais destacado é a necessidade de estabelecimento de um modelo mais perene de desenvolvimento da economia solidária nas universidades.

Nesse sentido, o processo de institucionalização do pensar e se relacionar com a economia solidária tendo por base as incubadoras poderiam ser repensadas. Primeiro porque, como no caso específico da UFGD e da UEMS, onde as incubadoras são órgãos diretamente ligados à administração central da universidade (ou à Pró-Reitoria de Extensão), as ações e o pensar a Economia Solidária vão variar em função das prioridades ou concepções políticas e educacionais das gestões em curso. Segundo, porque os fomentos provenientes exclusivamente de editais, principalmente quando articulados com outras áreas de conhecimento, podem gerar projetos nos quais a temática da economia solidária é um elemento secundário, ligado a outras linhas de pesquisa ou grupos com outras temáticas.

Para superar tais problemas, uma alternativa seria a criação de laboratórios de Economia Solidária, sob gestão de um corpo de professores (e não da administração central), como articulador dessa relação da universidade com a Economia Solidária. Esse laboratório, com seus projetos seria o sustentáculo das incubadoras, e não o contrário. Pode parecer que nessa situação as incubadoras deixariam de ter sua função de extensão priorizada. Esse receio, no entanto, é mais uma questão de compreensão da extensão, que a nosso ver deveria ser desenvolvida de forma integrada com a pesquisa e o ensino, e não como um serviço a ser prestado pela universidade.

Além disso, a institucionalização de um laboratório de Economia Solidária, poderia também dar sustentação para os processos de capacitação integrados com as rotinas cotidianas da universidade. Nesse sentido, os procedimentos de formação, ao 
invés de se configurarem como cursos de extensão (embora esses também possam ocorrer de maneira sistemática para tópicos específicos), se institucionalizariam melhor dentro do âmbito do ensino. O processo de relação com o poder público poderia ocorrer a partir de programas de especialização, de preferência na modalidade de $\mathrm{EAD}$, no qual os membros do poder público de diferentes cidades poderiam tanto adquirir os conteúdos conceituais por meio das aulas, quanto sustentar as discussões grupais, por meio de espaços virtuais de interação. Em casos de laboratórios mais desenvolvidos poderiam, inclusive, sustentar programas de pós-graduação stricto sensu, para promover um maior desenvolvimento dos alunos já envolvidos com o estudo do tema.

Da mesma forma, a compreensão sobre economia solidária na graduação poderia ocorrer a partir de disciplinas da graduação, inseridas como um dos eixos temáticos comuns aos cursos da universidade, pensados em uma perspectiva interdisciplinar, consideradas as particularidades de cada curso. Nesse caso, a estruturação de um conjunto de elementos em comum, definidos pelos pesquisadores dos Laboratórios de Economia Solidária, poderia gerar uma compreensão que é ao mesmo tempo comum e fundamentada sobre a economia solidária, mas articulada com as necessidades de cada curso. Tais ações, no entanto, se configuram como sugestão e precisariam, a partir de sua efetiva realização, serem também analisadas, para verificação de sua efetividade.

\section{REFERÊNCIAS}

CALBINO, D; PAULA, A.P.P. Economia Solidária: investigação sobre o estado da arte. Gestão Contemporânea, v. 10, n. 14, p. 371-397, 2013. Disponível em: https://www.redalyc.org/jatsRepo/3515/351557804004/html/index.html. Acesso em: 06 de dezembro de 2019.

CHAUÍ, M. Conformismo e Resistência: Aspectos da cultura popular no Brasil. São Paulo: Editora Brasiliense, 1986.

DåELIA, G.S.M. Estudo sobre o Comercio Justo em Glória de Dourados, Mato Grosso do Sul. Cadernos de Agroecologia, v. 7, n. 2, p. 1-5, 2012. Disponível em: http://revistas.aba-agroecologia.org.br/index.php/cad/article/view/13109/8714. Acesso em: 04 de dezembro de 2019.

FERNANDES, L.P. et all. Relato de experiência da formação da associação Sabores do Cerrado do assentamento Lagoa Grande, distrito de Itahum, Dourados, Mato Grosso do Sul. Realização, v. 1, n. 2, p. 60-64, 2014. Disponível em: 
http://ojs.ufgd.edu.br/index.php/realizacao/article/view/3281/1901. Acesso em: 04 de dezembro de 2019.

GATTAI, S., BERNARDES, M.A. Papel e responsabilidade da universidade no processo socioeducativo presente em movimentos de economia solidária. Revista de Administração Mackenzie, v. 14, n. 6, p. 58-81, 2013. Disponível em: http://www.scielo.br/scielo.php?script=sci_arttext\&pid=S1678-69712013000600004.

Acesso em: 10 de dezembro de 2019.

LOBTCHENKO et all. Sustentabilidade da Agricultura Familiar em Assentamentos Rurais da Região de Dourados, MS através do Agroextrativismo. Cadernos de Agroecologia, v. 13, n. 2, p. 1-8, 2018. Disponível em: http://cadernos.abaagroecologia.org.br/index.php/cadernos/article/view/2302/2076. Acesso em: $04 \mathrm{de}$ dezembro de 2019.

MASCARELLO, M.L.; MASCARELLO, L.E. Entre a fé, a família e à política: A economia solidária em Dourados ï MS. Outra Economia, v. 10, n. 18, p. 125-136, 2016. Disponível

em: https://revistaotraeconomia.org/index.php/otraeconomia/article/view/otra.2016.1018.11/ 5348. Acesso em: 04 de dezembro de 2019.

OLIVEIRA, T.C.S., ADDOR, F., MAIA, L. Incubadoras Tecnológicas de Economia Solidária como espaço de desenvolvimento de tecnologias e inovações sociais. Revista Tecnologia e Sociedade, v. 14, n. 32, v. 38-59, 2018. Disponível em: https://periodicos.utfpr.edu.br/rts/article/view/7855. Acesso em: 03 de dezembro de 2019.

OLIVEIRA, M.C.S.B., ZANIN, M. Economia Solidária: Uma temática em evolução nas dissertações e teses brasileiras. Revista Brasileira de Ciência, Tecnologia e Sociedade, v. $2, \quad$ n. $1, \quad$ pp. 181-193, 2011. Disponível em: http://www.revistabrasileiradects.ufscar.br/index.php/cts/article/viewFile/121/69.

Acesso em: 05 de dezembro de 2019.

PINHEIRO, D.C. O Estado da Arte da Produção Científica em Economia Solidária. Administração Pública e Gestão Social, v. 8, n. 2, p. 95-103, 2016. Disponível em: http://www.apgs.ufv.br/index.php/apgs/article/view/843\#.WOOfBE9Viko. Acesso em: 06 de dezembro de 2017.

PIRES, S.D. Empreendimento, Comunidade e Território: três objetos de incubação em Economia Solidária. Realização, v. 4, n. 8, p. 46-66, 2017. Disponível em: http://ojs.ufgd.edu.br/index.php/realizacao/article/view/6883/4317. Acesso em: 03 de dezembro de 2019.

PIRES, S.D. Perlaboração de mecanismos defensivos em relação ao trabalho em Empreendimentos de Economia Solidária. Desenvolve, v.7, n.1, p. 39-53, 2018. Disponível em: https://revistas.unilasalle.edu.br/index.php/desenvolve/article/view/3869/pdf. Acesso em: 03 de dezembro de 2019. 
RIEDO, I.G., RIBEIRO, C.R., CALARGE, T.C.C. A prática extensionista e a economia solidária na incubadora de tecnologias sociais e solidárias. Realização, v. 6, n. 11, p. 117 139, 2019. Disponível em: http://ojs.ufgd.edu.br/index.php/realizacao/article/view/9265/5376. Acesso em: 04 de dezembro de 2019.

SÁ, C.A.F. Economia Solidária em Mato Grosso do Sul: desafios e possibilidades. Monografia de Especialização em Gestão Empresarial. UNAES: Campo Grande, 2005. Disponível em: http://base.socioeco.org/docs/carlos_sa_es_no_ms_desafios_e_possibilidades.pdf. Acesso em: 04 de dezembro de 2019.

SILVA, S.P. O campo de pesquisa da economia solidária no Brasil: abordagens metodológicas e produção analítica. IPEA: Brasília, 2018. Disponível em: http://repositorio.ipea.gov.br/bitstream/11058/8255/1/TD 2361.pdf. Acesso em: 05 de junho de 2020.

SILVA, N.F.; ZANIN, M. Cenário das publicações em economia solidária por meio de estudos bibliométricos. II Congresso Nacional de Economia Solidária. São Carlos, 2018. Disponível em: http://www.conpes.ufscar.br/wpcontent/uploads/trabalhos/iiconpes/gt01/4/silva_nathalia_zanin_maria2.doc.pdf. Acesso em: 05 de junho de 2020.

THIOLLENT, Michel. A construção do conhecimento e metodologia de extensão. Cronos, v.3, n2, p. 65-71, 2002. Disponível em: https://periodicos.ufrn.br/cronos/article/view/15654/10730. Acesso em: 10 de dezembro de 2019.

TIRIBA, L. Ciência econômica e saber popular: Reivindicar o ñpopularò na economia e na educação. In: PICANÇO, I.; TIRIBA, L. (Orgs.). Trabalho e educação: arquitetos, abelhas e outros tecelões da economia popular solidária. Aparecida: Ideias \& Letras, 2004. p. 75-101.

VERÃO, M.F.R. Análise do perfil socioeconômico dos empreendimentos econômicos solidários em Dourados ï MS no período de 2007 a 2013. Monografia de Graduação, FACE/UFGD: $\quad$ Dourados, 2016.2 Disponível em: https://dspace.ufgd.edu.br/jspui/bitstream/123456789/674/1/MORISSONVER\%c3\%83 O.pdf. Acesso em: 04 de dezembro de 2019.

VICTÓRIA, L.B.G. O PRONINC e seus reflexos na ação social das Incubadoras Tecnológicas de Cooperativas. Dissertação de mestrado em Políticas Sociais. Pelotas: Universidade Católica de Pelotas. 2011. Disponível em: http://bdtd.ibict.br/vufind/Record/UCPe 2f8baf9cead822a99b29a98038c7b1b3. Acesso em: 06 de dezembro de 2019. 